Original Research Paper

\title{
Cariogenic Pathogen Scardovia Wiggsiae Screening Among Pediatric Orthodontic Patients: A Pilot Study
}

\author{
${ }^{1}$ Weston Milne, ${ }^{1}$ Ghazaleh Rezaei, ${ }^{2}$ Adam Whiteley and ${ }^{3}$ Karl Kingsley \\ ${ }^{I}$ Department of Clinical Sciences, \\ ${ }^{2}$ Department of Advanced Education in Orthodontics and Dentofacial Orthopedics, \\ University of Nevada, Las Vegas, School of Dental Medicine, 1700 W. Charleston, Las Vegas, Nevada, 89106, USA \\ ${ }^{3}$ Department of Biomedical Sciences, \\ University of Nevada, Las Vegas, School of Dental Medicine, \\ 1001 Shadow Lane, Las Vegas, Nevada, 89106, USA
}

Article history

Received: 16-07-2017

Revised: 22-08-2017

Accepted: 25-09-2017

Corresponding Author:

Karl Kingsley

Biomedical Sciences and Director of Student Research,

University of Nevada, Las

Vegas, School of Dental

Medicine, 1001 Shadow Lane

Las Vegas, Nevada, 89106, USA

Tel: (702)774-2623

Email: Karl.Kingsley@unlv.edu

\begin{abstract}
Dental caries remains one of the most prevalent oral health diseases in the United States, affecting nearly half of all children and a majority of adults. Most medically important cariogenic bacteria, including Streptococcus, Lactobacillus, Actinomyces and Veillonella species are well known, although recent evidence has identified the new cariogenic pathogen Scardovia wiggsiae ( $S$. wiggsiae) among children and minorities with severe early childhood caries. Based upon these new findings, the goal of this project was to determine the prevalence of this new cariogenic pathogen $S$. wiggsiae from a repository of previously collected pediatric saliva samples from orthodontic patients. DNA was isolated from previously collected saliva samples $(\mathrm{n}=48)$ and was subsequently screened for the presence of $S$. wiggsiae using Polymerase Chain Reaction (PCR) and primers designed specifically to distinguish this organism. Fifteen (15) samples tested positive for S. wiggsiae, representing $31.25 \%$ of the samples screened. As previous studies from this laboratory using adult orthodontic patients and pediatric nonorthodontic patients revealed prevalence of and 14 and $21.5 \%$, respectively - these findings suggest that the newly identified cariogenic pathogen $S$. wiggsiae may disproportionately affect pediatric orthodontic patients for reasons that are not well understood, which imply more detailed and focused research in this area is needed. As previous research has demonstrated that oral health status and caries risk may be related to education, income and socioeconomic status, these findings help to elucidate and contextualize the risks facing these populations.
\end{abstract}

Keywords: Scardovia Wiggsiae, Pediatric, Dental, Saliva, Caries

\section{Introduction}

Dental caries remains a big problem in the world and particularly in developed countries (Niederman et al., 2017). Despite the advances in oral health care products and services, there are many forces that may influence the rate and distribution of dental caries, especially among children (Ashi et al., 2017; Li et al., 2017). For example, the increased prevalence of sugar sweetened beverages, poor or non-existent dietary education and lack of dental health insurance have conspired to create a problem even among affluent societies (Sanghavi and Siddiqui, 2017; Shaban et al., 2017).
Orthodontic treatment has increased in popularity in Western countries- and is almost routine or commonplace in the US among teenagers and adolescents (Weir, 2017; Martonffy, 2015). Orthodontic brackets remain the most widely used form of treatment, which can be associated with decreased oral hygiene and increased risk of oral caries (Jurišić et al., 2017; Morita et al., 2014). The most detailed research studies have focused necessarily on the most widely accepted cariogenic pathogens, including Streptococcus mutans as well as Lactobacillus, Actinomyces and Veillonella. 
More recent studies, however, have demonstrated that other cariogenic pathogens may also be present and are now known to contribute significantly to dental caries (Costalonga and Herzberg, 2014; Tanner et al., 2011). This includes Scardovia wiggsiae, which was originally isolated from pediatric patients with severe early childhood caries but has more recently been found among other patients (Downes et al., 2010; Henne et al., 2015; Row et al., 2016). Some studies have even found $S$. wiggsiae among adult orthodontic patients, thereby highlighting the need to further study prevalence among pediatric orthodontic patients (Tanner et al., 2012; Streiff et al., 2015).

Due to the increased caries risk associated with orthodontic treatment in general and in pediatric patients more specifically, the goal of this study was to use an existing saliva repository to identify any pediatric orthodontic patient samples that could be screened for Scardovia wiggisae.

\section{Methods}

\section{Human Subjects}

Approval for this retrospective study of previously collected saliva samples titled "Retrospective investigation of Prevalence of Scardovia wiggsiae (SW) in pediatric orthodontic patients "(Protocol\#880427-1) was granted by the UNLV Office for the Protection of Research Subjects (OPRS) Institutional Review Board (IRB) on March 7, 2016. The original protocol for the collection of saliva samples titled "The Prevalence of Oral Microbes in Saliva from the University of Nevada Las Vegas (UNLV) School of Dental Medicine (SDM) pediatric and adult clinical population" (Protocol\#1502$5068 \mathrm{M}$ ) was reviewed and approved by the UNLV Office for the Protection of Research Subjects (OPRS) Institutional Review Board (IRB) on February 6, 2015.

In brief, parents or guardians were asked to participate in this study and Informed Consent was obtained. Pediatric patients were then asked for their voluntary participation and Pediatric Assent was also obtained. Participation was strictly voluntary and no remuneration was given to any subject. Patients were given a sterile saliva collection tube and asked to provide up to $5 \mathrm{~mL}$ of unstimulated saliva. Samples were then transferred to a biomedical laboratory for analysis.

\section{DNA Isolation}

The isolation of DNA from saliva samples was performed as previously described (Tiku et al., 2016; Flake et al., 2012). In brief, samples were processed using the GenomicPrep DNA isolation kit from Amersham Biosciences (Buckinghamshire, UK) using the manufacturer recommended protocol. The isolated DNA was suspended in $100 \mathrm{uL}$ of DNA hydration solution for quality and quantity analysis using absorbance ratio measurements at A260 and A280 nm.

\section{PCR Screening}

Polymerase Chain Reaction (PCR) screening was performed using the Fisher Scientific exACTGene complete PCR kit (Fair Lawn, NJ) and the Eppendorf Mastercycler (Hamburg, Germany), as previously described (Row et al., 2016; Streiff et al., 2015). The PCR positive control used to confirm the presence of human DNA from saliva samples was glyceraldehyde3- phosphate dehydrogenase (GAPDH) and the PCR positive control for the presence of bacterial DNA within each saliva sample was the $16 \mathrm{~S}$ rRNA universal primer. Screening for the cariogenic pathogen Scardovia wiggsiae was then accomplished using the following primers (Tanner et al., 2011; 2012):

GAPDH forward primer, ATCTTCCAGGAGCGAGATCC; $\mathrm{Tm}=66^{\circ} \mathrm{C}$ GAPDH reverse primer, ACCACTGACACGTTGGCAGT; $\mathrm{Tm}=70^{\circ} \mathrm{C}$

16S rRNA universal primer,

\section{ACGCGTCGACAGAGTTTGATCCTGGCT; $\mathrm{Tm}=76^{\circ} \mathrm{C}$}

$16 \mathrm{~S}$ rRNA universal GGGACTACCAGGGTATCTAAT; $\mathrm{Tm}=62^{\circ} \mathrm{C}$

S. wiggsiae forward primer, GTGGACTTTATGAATAAGC; $\mathrm{Tm}=55^{\circ} \mathrm{C}$

S. wiggsiae reverse primer, CTACCGTTAAGCAGTAAG; $\mathrm{Tm}=56^{\circ} \mathrm{C}$

In brief, each PCR reaction was performed using one ug of total DNA. The initial denaturation step ran for three minutes at $94^{\circ} \mathrm{C}$, with a total of 30 amplification cycles (C30) consisting of $30 \mathrm{sec}$ denaturation at $94^{\circ} \mathrm{C}$, $60 \mathrm{sec}$ of annealing at $55^{\circ} \mathrm{C}$ for $S$. wiggsiae, $66^{\circ} \mathrm{C}$ for GAPDH and $62^{\circ} \mathrm{C}$ for $16 \mathrm{~S}$ and $30 \mathrm{sec}$ of extension at $72^{\circ} \mathrm{C}$. Final extension was run for five minutes at $72^{\circ} \mathrm{C}$. The PCR reaction products were separated by gel electrophoresis using Reliant 4\% NuSieve ${ }^{\circledR}$ 3:1 Plus Agarose gels (Lonza: Rockland, Maine, USA). Bands were visualized by UV illumination of ethidiumbromide-stained gels and captured using a Kodak Gel Logic 100 Imaging System and 1D Image Analysis Software (Eastman Kodak: Rochester, New York, USA).

\section{Statistical Analysis}

Demographic data for the study sample are presented as absolute number $(\mathrm{n}=\mathrm{X})$ and using descriptive statistics (percentage or \%), which were compared to the clinic population using Chi-square analysis from GraphPad software (La Jolla, CA). Statistical significance was denoted as $\mathrm{p}<0.05$.

\section{Results}

Demographic analysis of the retrospective samples identified was performed (Table 1). 


\begin{tabular}{llll} 
Table 1: Demographic analysis of study sample & \\
\hline & $\begin{array}{l}\text { Study sample } \\
(\mathrm{n}=48)\end{array}$ & $\begin{array}{l}\text { Clinic } \\
\text { population }\end{array}$ & $\begin{array}{l}\text { Statistical } \\
\text { analysis }\end{array}$ \\
\hline $\begin{array}{l}\text { Sex } \\
\text { Female }\end{array}$ & $52.15 \%(\mathrm{n}=25)$ & $49.10 \%$ & $\begin{array}{l}\chi 2=3.601 \\
\mathrm{~d} . \mathrm{f}=1 \\
\mathrm{p}=0.0577\end{array}$ \\
$\begin{array}{l}\text { Male } \\
\text { Race/Ethnicity }\end{array}$ & $47.9 \%(\mathrm{n}=23)$ & $50.90 \%$ & \\
& & & $\chi 2=0.037$ \\
White & $41.7 \%(\mathrm{n}=20)$ & $41.40 \%$ & $\mathrm{~d} . \mathrm{f}=1$ \\
$\begin{array}{l}\text { Minority } \\
\text { Hispanic }\end{array}$ & $58.3 \%(\mathrm{n}=28)$ & $58.60 \%$ & $\mathrm{p}=0.8473$ \\
Black & $35.4 \%(\mathrm{n}=17)$ & $35.90 \%$ & \\
Asian & $18.8 \%(\mathrm{n}=9)$ & $13.10 \%$ & \\
$\begin{array}{l}\text { Age } \\
12-17 \text { years }\end{array}$ & $4.2 \%(\mathrm{n}=2)$ & $4.20 \%$ & \\
$18+$ years & Ave. $=16.6 \mathrm{yrs}+/-1.4$ & $15.8 \mathrm{yrs} .+/-3.2$ & \\
& & 21.4 yrs. $+/-2.4$ & \\
& Range $(11-17$ yrs. $)$ & Range $(11-38)$ & \\
\hline
\end{tabular}

Table 2: DNA isolation and analysis

\begin{tabular}{llll}
\hline & DNA recovery & Quantification & Purity \\
\hline Study samples & $\mathrm{n}=48$ & $261.3 \mathrm{ng} / \mathrm{uL}$ & $\mathrm{A} 260: \mathrm{A} 280$ \\
& $(100 \%)$ & $+/-63.1(\mathrm{STD})$ & $\begin{array}{l}1.62-2.00 \\
\text { Ave }=1.74\end{array}$ \\
& & & \\
$\begin{array}{l}\text { Manufacturer } \\
\text { range }\end{array}$ & $95-100 \%$ & $100-1000 \mathrm{ng} / \mathrm{uL}$ & $\begin{array}{l}1.50-2.00 \\
\text { Purity } 1.70-2.00\end{array}$ \\
\hline
\end{tabular}

Table 3: Analysis of Scardovia-positive and-negative samples

\begin{tabular}{|c|c|c|c|}
\hline & $\begin{array}{l}\text { SW-positive } \\
(n=15)\end{array}$ & $\begin{array}{l}\text { SW-negative } \\
(\mathrm{n}=33)\end{array}$ & $\begin{array}{l}\text { Statistical } \\
\text { analysis }\end{array}$ \\
\hline Sex & & & $\chi 2=1.297$ \\
\hline Female & $53.3 \%(\mathrm{n}=8)$ & $51.5 \%(n=17)$ & d.f. $=1$ \\
\hline Male & $46.6 \%(n=7)$ & $48.5 \%(n=16)$ & $p=0.2547$ \\
\hline Race/Ethnicity & & & $\chi 2=2.358$ \\
\hline White & $40 \%(n=6)$ & $42.4 \%(n=14)$ & d.f. $=1$ \\
\hline Minority & $60 \%(n=9)$ & $57.6 \%(n=19)$ & $\mathrm{p}=0.1246$ \\
\hline
\end{tabular}

This analysis revealed that the percentage of females and males within the study sample $(52 \%$ and $48 \%$, respectively) was not significantly different from the overall composition of the clinic population (49\% and $51 \%, \mathrm{p}=0.0577)$. The reported racial and ethnic background of the study sample isolates was also similar to the overall clinic population with approximately $2 / 5$ of the sample White and $3 / 5$ of the sample from non-White or minority backgrounds $(p=0.8473)$. The study sample contained only pediatric orthodontic patients averaging 16.6 years of age, while the overall orthodontic clinic population is comprised of both pediatric and adult populations, with an average age of pediatric orthodontic patients equal to 15.8 years.

The pediatric orthodontic saliva samples that were identified from the existing repository were then processed to isolate DNA contained within the sample, including bacterial and human DNA (Table 2). DNA was successfully isolated from all study samples $(n=48)$ with an average concentration of $261.3 \mathrm{ng} / \mathrm{uL}$, which is within the acceptable range provided by the manufacturer.

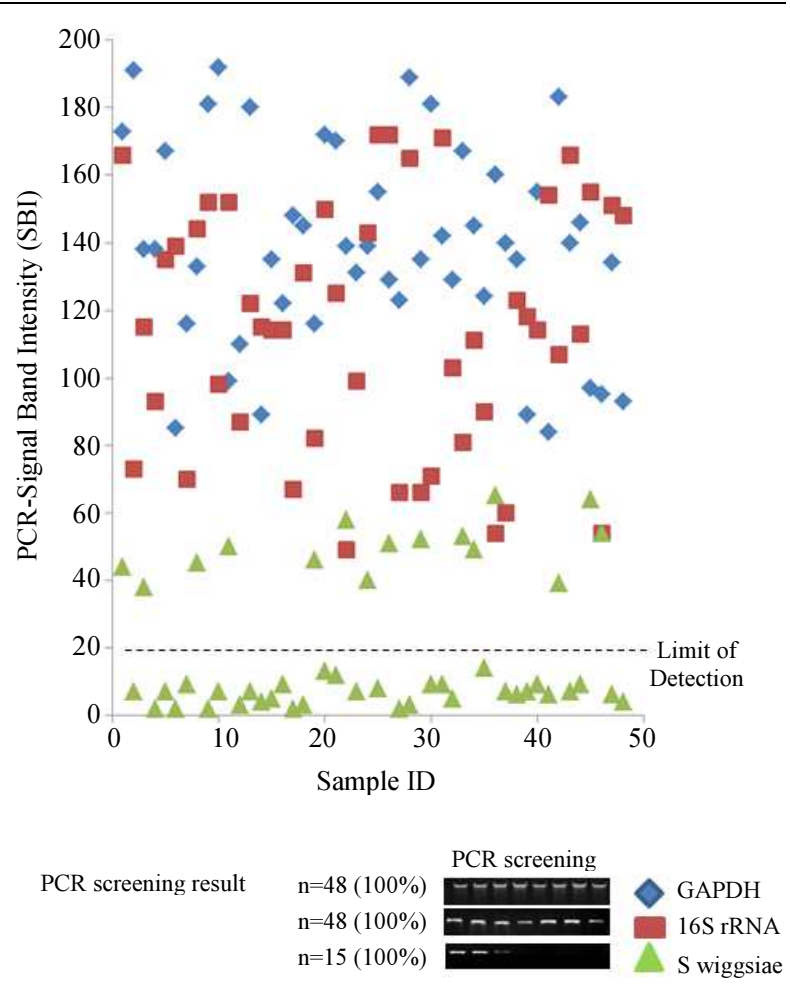

Fig. 1: PCR screening for $S$. wiggsiae. DNA from each isolate was screened for human (GAPDH) and bacterial (16S rRNA) revealing positive results for all samples $(n=48)$. PCR results for $S$. wiggsiae revealed a subset $(n=15 / 48$ or $31.25 \%$ ) harbored DNA from this organism

The purity of each sample was determined using the ratio of absorbance measurements at A260 nm and A280 nm, which ranged between 1.62 and 2.00 with an average of 1.74 - which allowed for the subsequent screening of all identified samples using PCR.

The isolates from each of the saliva samples were then screened using PCR for the positive control genes for human (GAPDH) and bacterial (16S rRNA) DNA (Fig. 1). The PCR results for GAPDH revealed that each sample had detectable human DNA $(n=48)$, while similar positive results were found for 16S rRNA (bacterial DNA, $\mathrm{n}=48$ ), confirmation that all samples contained both human and bacterial DNA. The PCR screening results for $S$. wiggsiae revealed that approximately one-third $(n=15 / 48$ or $31.25 \%$ ) of these isolates harbored this organism.

A more detailed analysis of the $S$. Wiggsiae (SW)positive and SW-negative samples was performed to determine if sex or race/ethnicity were associated with a positive screening result (Table 3 ). The percentage of SW-positive and SW-negative samples that were female $(53.3 \%$ and $51.5 \%$, respectively) were comparable and not significantly different $(\mathrm{p}=0.2547)$. In addition, the percentage of SW-positive and SWnegative samples that were derived from minority patients $(60 \%$ and $57.6 \%)$ were also similar and not significantly different $(\mathrm{p}=0.1246)$. 


\section{Discussion}

Due to the increased caries risk associated with orthodontic treatment in general and in pediatric patients more specifically, the goal of this study was to use an existing saliva repository to identify any pediatric orthodontic patient samples that could be screened for Scardovia wiggisae. The results of this retrospective pilot study have revealed that a significant subset of these patients (approximately one-third) harbor DNA from this organism. These results are important as the other screening of non-Orthodontic samples from this patient population revealed a prevalence of $26.3 \%$ among pediatric patients and only $24.7 \%$ among adult patients (Row et al., 2016). The only screening of orthodontic patients from this patient pool was performed only among adult patients, revealing Scardovia among 14\% of those adult Orthodontic patients compared with 19\% among an age-matched sample of non-Orthodontic adult controls (Streiff et al., 2015).

Although preliminary in nature, the results of this pilot study may suggest a higher percentage of pediatric orthodontic patients harbor oral S. wiggsiae, which may be a significant concern due to the cariogenic potential of this organism. As more studies evaluate the prevalence of Scardovia among adolescent and pediatric patient populations, more research will be needed to determine if oral alterations (such as orthodontic brackets) are capable of altering the growth and viability of these organisms (Eriksson et al., 2017; Richards et al., 2017). These data will be critically important for dental clinicians and orthodontists to more accurately assess the oral health and disease potential among their patients seeking orthodontic treatment and therapy.

Although these data provide novel data regarding this patient population, this study had many limitations that must also be considered. For example, the retrospective nature of this study significantly limited the size of the potential patient pool that could be evaluated and screened. In addition, these samples were collected as part of a convenience sample that was based exclusively within a public dental school setting that focuses primarily on low income and minority patient populations (Streiff et al., 2015; Tiku et al., 2016; Flake et al., 2012). Based upon this information, it is possible that the results of this initial pilot study may be biased due to the nature of this patient populationalthough more studies will be needed to determine if these factors may be relevant.

\section{Conclusion}

As previous studies from this laboratory using adult orthodontic patients and pediatric non-orthodontic patients revealed lower prevalence - the findings of this current pilot study suggest that the newly identified cariogenic pathogen $S$. wiggsiae may disproportionately affect pediatric orthodontic patients for reasons that are not well understood. As previous research has demonstrated that oral health status and caries risk may be related to education, income and socioeconomic status, these findings help to elucidate and contextualize the risks facing these populations - although more research will be needed to fully understand these results.

\section{Acknowledgement}

Dr. Kingsley and Dr. Whiteley would like to thank the Department of Advanced Education in Orthodontics and Dentofacial Orthopedics at the University of Nevada, Las Vegas, School of Dental Medicine for research funds to complete this pilot study.

\section{Author Contributions}

Weston Milne and Ghazaleh Rezaei: Were responsible for the sample processing and data collection.

Adam Whiteley and Karl Kingsley: Were responsible for the data analysis and manuscript preparation.

\section{Conflicts of Interest}

The authors declare there are no conflicts of interest to report.

\section{References}

Ashi, H., C. Lara-Capi, G. Campus, G. Klingberg and P. Lingström, 2017. Sweet taste perception and dental caries in 13- to 15-Year-Olds: A multicenter crosssectional study. Caries Res., 51: 443-450. PMID: 28738384

Costalonga, M. and M.C. Herzberg, 2014. The oral microbiome and the immunobiology of periodontal disease and caries. Immunol Lett., 162: 22-38. PMID: 25447398

Downes, J., M. Mantzourani, D. Beighton, S. Hooper and M.J. Wilson et al., 2010. Scardovia wiggsiae sp. nov., isolated from the human oral cavity and clinical material and emended descriptions of the genus Scardovia and Scardovia inopinata. Int. J. Syst. Evol. Microbiol., 61: 25-9. PMID: 20139283

Eriksson, L, P. LifHolgerson and I. Johansson, 2017. Saliva and tooth biofilm bacterial microbiota in adolescents in a low caries community. Sci. Rep., 7: 5861. PMID: 28724921

Flake, C., J. Arafa, A. Hall, E. Ence and K. Howard, 2012. Screening and detection of Human Papillomavirus (HPV) high-risk strains HPV16 and HPV18 in saliva samples from subjects under 18 years old in Nevada: A pilot study. BMC Oral Health, 12: 43. PMID: 23088565 
Henne, K., A. Rheinberg, B. Melzer-Krick and G. Conrads, 2015. Aciduric microbial taxa including Scardovia wiggsiae and Bifidobacterium spp. in caries and caries free subjects. Anaerobe, 35: 60-5. PMID: 25933689

Jurišić, S., Ž. Verzak, G. Jurišić and H. Jurić, 2017. Assessment of efficacy of two chlorhexidine mouthrinses on oral hygiene and gingival health in adolescents wearing two types of orthodontic brackets. Int. J. Dent. Hyg. PMID: 28657133

Li, L.W., H.M. Wong and C.P. McGrath, 2017. Longitudinal association between obesity and dental caries in adolescents. J. Pediatr., S0022-3476: 30900-9. PMID: 28728812

Martonffy, A.I., 2015. Oral health: Orthodontic treatment. FP Essent., 428: 22-6. PMID: 25594451

Morita, Y., S. Imai, A. Hanyuda, K. Matin and N. Hanada et al., 2014. Effect of silver ion coating of fixed orthodontic retainers on the growth of oral pathogenic bacteria. Dent. Mater. J., 33: 268-74. PMID: 24614999

Niederman, R., S.S. Huang, A.L. Trescher and S. Listl, 2017. Getting the Incentives Right: Improving Oral Health Equity With Universal School-Based Caries Prevention. Am. J. Public Health, 107: S50-S55. PMID: 28661798

Richards, V.P., A.J. Alvarez, A.R. Luce, M. Bedenbaugh and M.L. Mitchell et al., 2017. Microbiomes of sitespecific dental plaques from children with different caries status. Infect. Immun., 85: pii: e00106-17. PMID: 28507066

Row, L., M.R. Repp and K. Kingsley, 2016. Screening of a pediatric and adult clinic population for caries pathogen Scardovia Wiggsiae. J. ClinPediatr Dent., 40: 438-444. PMID: 27805882
Sanghavi, A. and N.J. Siddiqui, 2017. Advancing oral health policy and advocacy to prevent childhood obesity and reduce children's consumption of sugarsweetened beverages. J. Public Health Dent. PMID: 28708302

Shaban, R., S. Kassim and W. Sabbah, 2017. Socioeconomic inequality in the provision of specific preventive dental interventions among children in the UK: Children's Dental Health Survey 2003. Br. Dent. J., 222: 865-869. PMID: 28703180

Streiff, B.J., M. Seneviratne and K. Kingsley, 2015. Screening and prevalence of the novel cariogenic pathogen Scardovia wiggsiae among adult orthodontic and non-orthodontic patient saliva samples. Int. J. Den. Oral Health.

Tanner, A.C., A.L. Sonis, P. LifHolgerson, J.R. Starr and Y. Nunez et al., 2012. White-spot lesions and gingivitis microbiotas in orthodontic patients. J. Dent. Res., 91: 853-8. PMID: 22837552

Tanner, A.C., R.L. Jr Kent., P.L. Holgerson, C.V. Hughes and C.Y. Loo et al., 2011. Microbiota of severe early childhood caries before and after therapy. J. Dent. Res., 90: 1298-305. PMID: 21868693

Tiku, V., C.J. Todd and K. Kingsley, 2016. Assessment of oral human papillomavirus prevalence in a multiethnic pediatric clinic population. Compend Contin. Educ. Dent., 37: e1-e4.PMID: 27875050

Weir, T., 2017. Clear aligners in orthodontic treatment. Aust. Dent. J., 1: 58-62. PMID: 28297094 